\title{
Unruptured Carotid Artery Aneurysms Presenting with Symptoms of Mass Effect: Outcome after Selective Coiling, Parent Vessel Occlusion, and Flow Diversion
}

I this issue, Szikora et $\mathrm{al}^{1}$ report some interim results of their cohort of patients with unruptured aneurysms treated with the Pipeline flow diverter (Covidien, Irvine California) without additional coiling of the sac. Special attention is given to the influence of the flow-diverter treatment on the evolution of symptoms of mass effect caused by the treated internal carotid artery aneurysm in 17 patients. On follow-up, in 16 of 17 patients, symptoms of mass effect, such as reduced visual acuity, double vision caused by cranial nerve palsy, or even hemiparesis, decreased or resolved completely. The authors correctly concluded that endovascular flow diversion is highly effective in resolving compression syndromes caused by unruptured aneurysms. In the "Discussion," the authors stated, "This goal is difficult to achieve with conventional endovascular techniques." However, this statement is not true.

In the past, we have studied the influence of conventional endovascular techniques such as parent vessel occlusion (PVO) and selective coiling on symptoms of mass effect caused by different types of ruptured and unruptured aneurysms. ${ }^{2-4}$ Both PVO and selective coiling appeared to be very effective in the alleviation of symptoms of mass effect caused by unruptured large or giant aneurysms of the internal carotid artery in the cavernous and ophthalmic segments. ${ }^{2}$ Of 17 aneurysms treated with selective coiling, symptoms of cranial nerve dysfunction resolved in 3 , improved in 10 , and remained unchanged in 4 . Of 31 aneurysms treated with internal carotid artery occlusion, cranial nerve dysfunction resolved in 19, improved in 9, and remained unchanged in 3 . The difference between the 2 modalities was not significant. In another study, ${ }^{3}$ we evaluated the recovery of posterior communicating artery-induced oculomotor palsy in 21 patients. After coiling, in 19 of 21 patients, oculomotor palsy improved or resolved completely. Complete recovery was more likely with initial partial dysfunction of the nerve. In a third study, ${ }^{4}$ we evaluated the clinical outcome of 56 partially thrombosed aneurysms presenting with symptoms of mass effect and treated with parent vessel occlusion $(n=30)$ or selective coiling $(n=26)$. Complete recovery in this special subset of aneurysms more often occurred after PVO than after coiling ( 12 of 26 versus 5 of $30, P<.02$ ). Aneurysm size reduction occurred more often after PVO (17 of 18 versus 2 of 28 ,
$P<.001)$. Five basilar tip aneurysms continued to grow after coiling, resulting in death in 3 patients.

From these follow-up studies comprising more than 100 patients with aneurysms presenting with mass effect, it is obvious that most patients do well after treatment with conventional endovascular techniques such as PVO and selective coiling, with the exception of some coiled patients with partially thrombosed large or giant basilar tip aneurysms.

The good results for symptoms of mass effect after flow diverting reported in the small patient group of Szikora et al ${ }^{1}$ thus cannot be an argument in support of this technique when PVO or selective coiling is possible as well. The use of flow diverters for unruptured aneurysms is a promising but insufficiently evaluated technique, with many potential disadvantages and a relatively high risk of complications, both in the short and long term. ${ }^{5-8}$ Flow diversion is complicated by the necessity of aggressive antithrombotic treatment and potential acute or delayed thrombosis of the parent artery in the case of insufficient antiaggregation. When delayed internal carotid artery occlusion occurs in a patient with insufficient collaterals, it will invariably lead to serious morbidity or even death. In 2 studies comprising almost 750 patients with unruptured aneurysms treated with flow diverters, procedural morbidity was approximately $5 \%$ and mortality, another $5 \%$, adding up to an alarming $10 \% .{ }^{7,8}$ In contrast, complications of PVO or selective coiling for unruptured aneurysms are generally less than $1 \%$. $^{2,9,10}$

Apart from the far better safety profile, conventional endovascular techniques are usually much cheaper than flow diversion. In this time of increasing pressure on hospital budgets, the price may become an important secondary argument for refraining from flow diversion. In the Netherlands, Belgium, and Germany, the price for a single Pipeline flow diverter varies between $€ 9750$ and $€ 14,000$, and in the United States, the price tag is $\$ 12,490 .{ }^{11}$ According to the report by Szikora et al, ${ }^{1}$ all except 1 patient needed 2-15 devices for the treatment of their aneurysms. Device costs thus can be more than $€ 200,000$ to treat a single aneurysm. In contrast, for comparison, a detachable balloon to occlude the internal carotid artery costs $€ 120$.

In patients presenting with symptoms of mass effect of an unruptured ICA aneurysm, our first goal is to do no harm. A 
treatment strategy with ICA occlusion when tolerated and selective coiling when necessary has a very low complication rate approaching $0 \%$. Both techniques are equally effective in alleviating symptoms of mass effect. Flow diversion may also be as effective for the mass effect as the conventional techniques but has a far higher complication rate and is much more expensive. As such, flow diversion is not an alternative for proved endovascular techniques.

\section{REFERENCES}

1. Szikora I, Marosfoi M, Salomvary B, et al. Resolution of mass effect and compression symptoms following endoluminal flow diversion for the treatment of intracranial aneurysms. AJNR Am J Neuroradiol 2013;34:935-39

2. van Rooij WJ, Sluzewski M. Unruptured large and giant carotid artery aneurysms presenting with cranial nerve palsy: comparison of clinical recovery after selective aneurysm coiling and therapeutic carotid artery occlusion. AJNR Am J Neuroradiol 2008;29:997-1002

3. Hanse MC, Gerrits MC, van Rooij WJ, et al. Recovery of posterior communicating artery aneurysm-induced oculomotor palsy after coiling. AJNR Am J Neuroradiol 2008;29:988-90

4. Ferns SP, van Rooij WJ, Sluzewski M, et al. Partially thrombosed intracranial aneurysms presenting with mass effect: long-term clinical and imaging follow-up after endovascular treatment. AJNR Am J Neuroradiol 2010;31:1197-205
5. Turowski B, Macht S, Kulcsar Z, et al. Early fatal hemorrhage after endovascular cerebral aneurysm treatment with a flow diverter (SILK-stent): do we need to rethink our concepts? Neuroradiology 2011;53:37-41

6. Briganti F, Napoli M, Tortora F, et al. Italian multicenter experience with flow-diverter devices for intracranial unruptured aneurysm treatment with periprocedural complications: a retrospective data analysis. Neuroradiology 2012;54:1145-52

7. Berge J, Biondi A, Machi P, et al. Flow-diverter Silk stent for the treatment of intracranial aneurysms: 1-year follow-up in a multicenter study. AJNR Am J Neuroradiol 2012;33:1150-55

8. Velioglu M, Kizilkilic $\mathrm{O}$, Selcuk $\mathrm{H}$, et al. Early and midterm results of complex cerebral aneurysms treated with Silk stent. Neuroradiology 2012;54:1355-65

9. van Rooij WJ, Sluzewski M. Endovascular treatment of large and giant aneurysms. AJNR Am J Neuroradiol 2009;30:12-18

10. van Rooij WJ. Endovascular treatment of cavernous sinus aneurysms. AJNR Am J Neuroradiol 2012;33:323-26

11. Cloft HJ. Capitalism and commodities: my two cents. AJNR Am J Neuroradiol 2013 Mar 14. [Epub ahead of print]

W.J. van Rooij

M. Sluzewski

Department of Radiology St. Elisabeth Ziekenhuis Tilburg, the Netherlands

http://dx.doi.org/10.3174/ajnr.A3594 